\title{
Molecular fingerprinting of isolates of the genus Peptostreptococcus using rRNA genes from Escherichia coli and $P$. anaerobius
}

\author{
LAI-KING NG* and Jo-ANNe R. Dillon \\ National Laboratory for Sexually Transmitted Diseases, Laboratory Centre for Disease Control, \\ Health and Welfare Canada, Ottawa, Ontario, Canada K1A OL2
}

(Received 10 February 1991; accepted 19 February 1991)

\begin{abstract}
Restriction fragment length polymorphisms (RFLPs) of rRNA genes were evaluated as a tool for intra- and interspecies differentiation of Peptostreptococcus isolates. RFLPs from a collection of 20 clinical isolates and five ATCC strains representing five Peptostreptococcus spp. (P. anaerobius, $P$. asaccharolyticus, $P$. magnus, $P$. micros and $P$. prevotii) were obtained by hybridization of Southern blots of HindIII- or EcoRI-digested genomic DNA with three probes: probe $A, a$ $0.98 \mathrm{~kb}$ HindIII fragment with a partial 16S rRNA gene sequence from $P$. anaerobius ATCC 27337; probe B, cloned Escherichia coli rrnB operon in plasmid pKK3535; and probe C, E. coli 16S and 23S rRNA. The hybridization patterns varied, but all yielded RFLPs useful for both intra- and inter-species differentiation. RFLPs of $\boldsymbol{P}$. asaccharolyticus clinical isolates were closely related to each other and differed significantly from those of the ATCC type strains. The profiles of $P$. prevotii differed from those of the other four species studied, and based on the HindIII- and EcoRI-generated RFLPs, the strains in this species are more heterogeneous than the other four species studied.
\end{abstract}

\section{Introduction}

Most female genital tract infections, including the classic sexually transmitted diseases, are polymicrobial in nature (Garber \& Chow, 1989). The most common anaerobes found in these infections are Peptostreptococcus and Bacteroides spp. (Garber \& Chow, 1989; Sweet, 1986). The relative importance of Peptostreptococcus spp. in mixed anaerobic infections has been studied (Brook \& Walker, 1984) and it has been proposed that these organisms play a synergistic role in polymicrobial female genital tract infections (Garber \& Chow, 1989). Besides their frequent association with mixed anaerobic infections, peptostreptococci have also been isolated in pure culture from soft tissue infections (Bougault et al., 1980), suggesting that they could also be the primary aetiological agent of these infections.

Although the importance of the indigenous cervicovaginal flora both in health and in disease has become increasingly recognized, the pathogenic potential of specific microbes, including Peptostreptococcus spp. has been difficult to assess. This is partly due to problems in the sampling, culturing, identification and taxonomic classification of these organisms from clinical specimens

Abbreviation: RFLP, restriction fragment length polymorphism.
(Brook, 1987; Mardh \& Westrom, 1984). In clinical laboratories, anaerobic Gram-positive cocci are often not differentiated at the species level when they are isolated from polymicrobic infections because they are frequently considered either as contaminants due to their presence as normal flora or as less significant pathogens than Bacteroides (Brook, 1987; Bougault et al., 1980; Finegold, 1989; Murdoch et al., 1988). Recently, the genus Peptostreptococcus has undergone taxonomic reclassification and now includes several species which were previously classified as Peptococcus (Ezaki et al., 1983; Moore et al., 1987). The differentiation of Peptostreptococcus micros from $P$. magnus based on phosphatase tests and electrophoretic patterns of soluble protein has made it difficult to reliably discriminate between these species (Moore et al., 1987). Although an identification system (RapID ANA, Mercia Diagnostics) based on pre-formed enzyme detection has been used to reliably identify $P$. anaerobius and $P$. asaccharolyticus, this system was unable to distinguish $P$. magnus from $P$. micros (Murdoch et al., 1988).

At present, there is no definitive correlation between specific Peptostreptococcus species or strains and any type of clinical infection (Finegold, 1989; Bougault et al., 1980). The role of Peptostreptococcus as an emerging, opportunistic or synergistic pathogen in causing specific 
anaerobic infections remains unclear. In order to determine its specific pathogenic role in causing infections it is necessary to carry out correlational studies of specific species or strains to properly diagnosed infections. This will be possible only if reliable differentiation systems for these strains are first developed. Serotyping and plasmid profile analysis were attempted and were not useful methods for strain differentiation (Smith et al., 1986; Ng \& Dillon, 1989). However, molecular typing schemes based on DNA fingerprinting have not been explored. In this study, restriction fragment length polymorphism (RFLP) of rRNA ( $r r n)$ operons of Peptostreptococcus was investigated as a tool for intraand inter-species differentiation of five Peptostreptococcus species.

\section{Methods}

Strains and culture conditions. Twenty Peptostreptococcus isolates comprising five species, obtained from the culture collection (courtesy of E. P. Ewan) of the National Laboratory for General Bacteriology (Laboratory Centre for Disease Control, Ottawa), and eight ATCC strains were included in this study (see Table 1). The speciation of the strains was re-confirmed using the VPI system (Holdeman et al., 1977). Escherichia coli JM83 was used as host for cloning experiments with the plasmid vector pUC9.

Stock cultures were either stored at $-70{ }^{\circ} \mathrm{C}$ in Brain Heart Infusion (BHI) broth with $20 \%(\mathrm{v} / \mathrm{v})$ glycerol or were lyophilized in $2 \%(\mathrm{w} / \mathrm{v})$ skim milk. Peptostreptococci were subcultured on BHI agar supplemented with $5 \%(\mathrm{v} / \mathrm{v})$ sheep blood, vitamin $\mathrm{K}\left(1 \mathrm{mg} \mathrm{l}^{-1}\right)$ and $0.1 \%$ haemin and incubated for $16-24 \mathrm{~h}$ at $37^{\circ} \mathrm{C}$ under anaerobic conditions $\left(5 \% \mathrm{CO}_{2}, 5 \% \mathrm{H}_{2}\right.$ and $\left.90 \% \mathrm{~N}_{2}\right)$.

Isolation of chromosomal DNA from Peptostreptococcus spp. For isolation of chromosomal DNA, $25 \mathrm{ml}$ Peptone Yeast Extract (PY) broth was inoculated with confluent growth from an entire BHI agar plate and incubated at $37^{\circ} \mathrm{C}$ anaerobically. After $24 \mathrm{~h}$, the PY broth culture was transferred to $225 \mathrm{ml}$ fresh PY broth and incubated for a further $24 \mathrm{~h}$. Because the peptostreptococcal cell wall is not susceptible to lysozyme alone (Ng \& Dillon, 1989), penicillin G (Sigma) in PY broth was added to cultures, at a final concentration of one-sixth of the minimal inhibitory concentration (MIC) of the specific isolate (see Table 1) 2-4 h prior to harvesting, to facilitate lysis. The MICs of penicillin G for ATCC strains were not determined in this study. The concentration of penicillin $G$ to be used for these strains was determined by growing them in $5 \mathrm{ml} P Y$ broth containing twofold dilutions $\left(0.002-0.02 \mathrm{mg} \mathrm{t}^{-1}\right)$ of the antibiotic. All ATCC strains yielded the highest amount of DNA from cell lysis if $0.004 \mathrm{mg}$ penicillin $\mathrm{G}^{-1}$ was used.

After 2-4 h of incubation, the cells were harvested by centrifugation for $10 \mathrm{~min}$ at 10000 r.p.m. in a GSA rotor, Sorvall RC5C centrifuge. They were then resuspended in $5 \mathrm{ml}$ TE (10 mM-Tris, pH 8.0, $1 \mathrm{mM}$ EDTA) buffer with $25 \%(\mathrm{w} / \mathrm{v})$ sucrose. Lysozyme $\left(3 \mathrm{mg} \mathrm{ml}^{-1}\right)$ was added, followed, after incubation for $30 \mathrm{~min}$ at $37^{\circ} \mathrm{C}$, by proteinase $\mathrm{K}$ $\left(0.2 \mathrm{mg} \mathrm{ml}^{-1}\right)$ and sodium dodecyl sulphate (SDS; $0.5 \%$, w/v, final concentration), with incubation at $37^{\circ} \mathrm{C}$ for a further $30 \mathrm{~min}$. The SDS concentration was then increased to $1 \%$. If complete lysis, as judged visually by clearing of cell suspension and increased viscosity, was not achieved, the cells were heated at $55^{\circ} \mathrm{C}$ until complete lysis was observed. The lysate was deproteinated with isoamyl alcohol/chloro-
Table 1. Peptostreptococcus strains (clinical isolates and ATCC strains) used in this study and their susceptibility to penicillin $G$

\begin{tabular}{|c|c|c|c|}
\hline Species & $\begin{array}{c}\text { LCDC/ATCC } \\
\text { strain designation }\end{array}$ & $\begin{array}{l}\text { Strain no. in } \\
\text { this study }\end{array}$ & $\operatorname{MIC}\left(\mathrm{mg} \mathrm{l}^{-1}\right)^{*}$ \\
\hline$P$. anaerobius & $\begin{array}{l}\text { A } 18 \\
781233 \\
1981-75 \\
\text { ATCC } 27337\end{array}$ & $\begin{array}{l}\text { P1 } \\
\text { P2 } \\
\text { P3 }\end{array}$ & $\begin{array}{l}1 \cdot 0 \\
0 \cdot 125 \\
0 \cdot 125 \\
\text { NT }\end{array}$ \\
\hline P. asaccharolyticus & $\begin{array}{l}\text { A133 } \\
\text { AN2-413A } \\
\text { AN2-419 } \\
\text { AN2-434C } \\
821758 \\
83-169 \\
\text { ATCC } 14963\end{array}$ & $\begin{array}{l}\text { PA1 } \\
\text { PA2 } \\
\text { PA3 } \\
\text { PA4 } \\
\text { PA5 } \\
\text { PA6 }\end{array}$ & $\begin{array}{l}0.063 \\
0.063 \\
0.063 \\
0.063 \\
0.063 \\
0.25 \\
\text { NT }\end{array}$ \\
\hline P. magnus & $\begin{array}{l}\text { A95 } \\
791273 \\
\text { AN2-970 } \\
\text { ATCC } 15794\end{array}$ & $\begin{array}{l}\text { PM1 } \\
\text { PM2 } \\
\text { PM3 }\end{array}$ & $\begin{array}{c}0.063 \\
0.125 \\
0.063 \\
\text { NT }\end{array}$ \\
\hline P. micros & $\begin{array}{l}\text { A53 } \\
\text { A120 } \\
\text { ATCC } 33270\end{array}$ & $\begin{array}{l}\text { PMI1 } \\
\text { PMI2 }\end{array}$ & $\begin{array}{c}0.063 \\
0.063 \\
\text { NT }\end{array}$ \\
\hline P. prevotii & $\begin{array}{l}\text { A129 } \\
83-125 \\
801478 \\
811556 \\
831883 \\
\text { AN2-253 } \\
\text { ATCC } 9321\end{array}$ & $\begin{array}{l}\text { PP1 } \\
\text { PP2 } \\
\text { PP3 } \\
\text { PP4 } \\
\text { PP5 } \\
\text { PP6 }\end{array}$ & \begin{tabular}{l}
0.25 \\
0.063 \\
0.063 \\
0.063 \\
0.5 \\
0.063 \\
\multicolumn{1}{c}{ NT }
\end{tabular} \\
\hline P. indolicus & ATCC 29427 & & NT \\
\hline P. productus & ATCC 27340 & & NT \\
\hline P. tetradius & ATCC 35098 & & NT \\
\hline
\end{tabular}

* MIC was determined using the agar dilution method as described previously (Ng \& Dillon, 1989).' NT, Not tested.

form $(1: 24, \mathrm{v} / \mathrm{v})$ extractions and then $0 \cdot 1 \mathrm{vol} .3 \mathrm{M}$-sodium acetate was added prior to precipitation with $95 \%(\mathrm{v} / \mathrm{v})$ ethanol at $-20{ }^{\circ} \mathrm{C}$. The DNA was further purified on an ethidium bromide/caesium chloride gradient (Sambrook et al., 1989). The purified DNA was resuspended and stored in $0.1 \times \mathrm{SSC}$ (Sambrook et al., 1989) at $4{ }^{\circ} \mathrm{C}$.

Cloning of $r R N A$ genes from $P$. anaerobius. DNA fragments from HindIII digestion of $P$. anaerobius ATCC 27337 chromosomal DNA were cloned into the HindIII site of pUC9, and transformed into E. coli JM83. To confirm that the recombinant clones carried $P$. anaerobius chromosomal DNA, the DNA used for cloning was end-labelled with $\left[\gamma^{-32} \mathrm{P}\right] \mathrm{ATP}$ and hybridized to $P$. anaerobius ATCC 27337 using dot-blot hybridization. The positive controls for the dot-blot hybridization included $P$. anaerobius clinical isolates (P1, $\mathrm{P} 2$ and $\mathrm{P} 3$ ) and the negative controls included E. coli JM83 with pUC 9 and the ATCC strains of the other seven Peptostreptococcus spp. listed in Table 1. Clones were screened for sequences of rRNA genes $(r r n)$ by hybridization with $[\gamma$ ${ }^{32} \mathrm{P}$ ]ATP end-labelled $16 \mathrm{~S}$ and 23S rRNA from $E$. coli (Boehringer Mannheim, BMC, Canada). Plasmid DNA was prepared by minialkali/SDS lysis (Birnboim \& Doly, 1979), subjected to electrophoresis, and transferred to a nylon membrane (Amersham) (Southern, 1975). The three clones (pLK 16, pLK51 and pLK 54) containing $r$ rn operon sequences were further characterized by hybridization with three ${ }^{32} \mathrm{P}$ end-labelled oligonucleotides containing universal prokaryotic $16 \mathrm{~S}$ 
rRNA sequences (BMC) that are complementary to positions 519-536 (primer 1), 907-926 (primer 2) and 1392-1406 (primer 3) of 16S rRNA of $E$. coli (Lane et al., 1975). The sizing of inserts and restriction endonuclease analysis were carried out by agarose gel electrophoresis and using $\lambda$ HindIII digests and $1 \mathrm{~kb}$ ladder (BRL, BRL/Gibco Canada) as molecular size markers.

DNA probes and labelling for $r$ RNA genes. To determine the RFLPs of rRNA genes, three probes were compared. Probe A was a HindIII fragment from plasmid pLK54 containing a 16S rRNA gene sequence of $P$. anaerobius ATCC 27337 . Probe B comprised the 7.2 kb BamHIPstI fragment from plasmid pKK 3535 which contained the entire $r r n$ operon of $E$. coli (Brosius et al., 1981). This fragment was digested with $E c o$ RI before labelling because preliminary experiments showed that the $7.2 \mathrm{~kb}$ Bam HI-Pst I fragment labelled by random priming did not hybridize to most of the restriction fragments which hybridized to probe $\mathrm{A}$ or $\mathrm{C}$, even at the low-stringency conditions. This problem was overcome by restriction of the $7.2 \mathrm{~kb}$ fragment with $E c o$ RI to produce smaller fragments before labelling. Probe $\mathrm{C}$ was a mixture of $16 \mathrm{~S}$ and 23S rRNA from $E$. coli (BMC). Specific fragments from plasmids pLK54 and pKK 3535 were extracted from low-melting-point agarose (BRL). Both probes A and B were labelled non-radiometrically (BMCDIG) with a random priming labelling kit purchased from BMC. rRNA (probe C) was end-labelled with [ $\gamma-{ }^{32}$ P]ATP (Sambrook et al., 1989). In our hands, rRNA probes labelled non-radiometrically using the end-tailing method with terminal transferase (BRL) were not as sensitive as ${ }^{32} \mathrm{P}$ end-labelled probes.

Fingerprinting by RFLPs. Chromosomal DNA from Peptostreptococcus spp. was digested with HindIII and EcoRI. The digested DNAs were heated at $65^{\circ} \mathrm{C}$ to release bound proteins and to prevent the annealing of sticky ends and then fractionated on a $0.8 \%$ or $0.7 \%$ agarose gel in Tris/acetate buffer (pH 7.8) at $50 \mathrm{~mA}$ for $16 \mathrm{~h}$ to obtain the restriction endonuclease profiles. The fractionated DNA in agarose gel was visualized by ethidium bromide staining and photographed under UV light. The restriction endonuclease profile determination required numerous agarose gel electrophoreses because the resolution of the large number of fragments was critically dependent on the amount of DNA loaded per lane.

Fractionated genomic DNA in an agarose gel was transferred to a nylon membrane (Amersham). The membrane-bound DNAs were hybridized with probes $\mathrm{B}$ and $\mathrm{C}$ at $50^{\circ} \mathrm{C}$ and with probe $\mathrm{A}$ at $63^{\circ} \mathrm{C}$. For ${ }^{32} \mathrm{P}$-labelled probe $\mathrm{C}$, the hybridization solution contained $5 \times \mathrm{SSC}$. $0.5 \%$ SDS and $5 \times$ Denhardt's solution (Sambrook et al., 1989). For non-radioactive probes $\mathrm{A}$ and $\mathrm{B}$, the hybridization solution was prepared according to the instructions of the manufacturer (BMC). These hybridization conditions were determined by preliminary experiments which showed that probe $A$ could be used under higher stringency than probes B and C. Although probe C ( ${ }^{32} \mathrm{P}$-labelled $16 \mathrm{~S}$ and $23 \mathrm{~S}$ rRNA) hybridized well with $P$. anaerobius DNA at $63{ }^{\circ} \mathrm{C}$, it failed to hybridize with DNA from other Peptostreptococcus spp. unless the hybridization temperature was lowered to $50^{\circ} \mathrm{C}$.

The sizes of the chromosomal DNA fragments which hybridized with the probes were determined by using $\lambda$ DNA digested with Hind III, KpnI and $X h o \mathrm{I}$ as molecular size markers. The mean sizes from at least two gels were obtained and recorded. For schematic representation of RFLPs, fragment sizes were transformed to a $\log _{10}$ scale (Pérolat et al., 1990). This method minimized the error in sizing large fragments with low mobility in $0.8 \%$ agarose gels and also provided easier visual comparison of fragments due to the non-linear mobility of various size fragments in agarose gel electrophoresis. The variation in the intensities of bands due to either difference in the degree of homology between the probe and the target DNA or the presence of doublets not resolved in agarose gel will not be observed in the schematic representation of RFLPs.

\section{Results}

\author{
Cloning and identification of $16 S \mathrm{rRNA}$ from \\ $P$. anaerobius
}

Three of 67 recombinant plasmids, designated pLK 16 , pLK51 and pLK54, contained inserts that hybridized with a mixture of $16 \mathrm{~S}$ and $23 \mathrm{~S}$ rRNA (probe C). Labelled chromosomal DNA of $P$. anaerobius ATCC 27337 hybridized with the positive controls of $P$. anaerobius strains but did not hybridize with the negative controls of E. coli and the other seven Peptostreptococcus spp. This probe also hybridized with the insert DNA in plasmids pLK16, pLK51 and pLK54, thus confirming the origin of the insert. The size of the HindIII insert from both pLK 16 and pLK51 was $0.84 \mathrm{~kb}$ and that of the insert from pLK 54 was $0.98 \mathrm{~kb}$. The three HindIII inserts also cross-hybridized with each other, indicating that they contained similar sequences or gene(s).

The clones were hybridized with primers 1 to 3 to establish which 16S rRNA conserved regions they contalned. The HindIII inserts from pLK16, pLK51 and pLK 54 hybridized with primer 3 (see Fig. 1, lanes F-H); none of them hybridized with primer 1, and only pLK54 hybridized with primer 2 . Thus, all three plasmids contained partial 16S rRNA sequence and pLK54 carried more 16S rRNA sequences than the smaller plasmids (data not shown). From the coordinates of $E$. coli $16 \mathrm{~S}$ rRNA sequences, pLK54 was estimated to contain about half of the 16S rRNA gene.

Restriction endonuclease analysis of pLK16, pLK51 and pLK54 showed that each of the HindIII inserts contained a single SmaI site. Each of the $0.84 \mathrm{~kb}$ HindIII inserts from pLK 16 and pLK 51 comprised a $0.45 \mathrm{~kb}$ and a $0.39 \mathrm{~kb} S m a I$ fragment, while the $0.98 \mathrm{~kb}$ insert from pLK 54 comprised 0.59 and $0.39 \mathrm{~kb} S m a I$ fragments (see Fig. 2). There were no internal sites within the HindIII inserts in these clones for endonucleases $A c c I, B a m H I$, $B g l I, B s t$ EII, Eco RI, HindII, SalI, SstI, SstII and TthIII. Therefore, the restriction endonuclease sites of the $16 \mathrm{~S}$ rRNA gene of $P$. anaerobius ATCC 27337 are different from those of the $16 \mathrm{~S}$ rRNA gene of $E$. coli in pKK3535, which contains BstEII, EcoRI, SalI, SstII and TthIII sites besides the $S m a$ I site (Brosius et al., 1981). From the restriction endonuclease analysis data, it was concluded that the clones pLK54 and pLK 16 were derived from two different $r r n$ operons on the same chromosome of $P$. anaerobius ATCC 27337 but pLK16 and pLK51 were probably from the same rrn operon. Plasmid pLK 54 was selected as one of the probes for the determination of RFLPs of $r r n$ operons of Peptostreptococcus isolates because it contained more 16S rRNA sequence. 


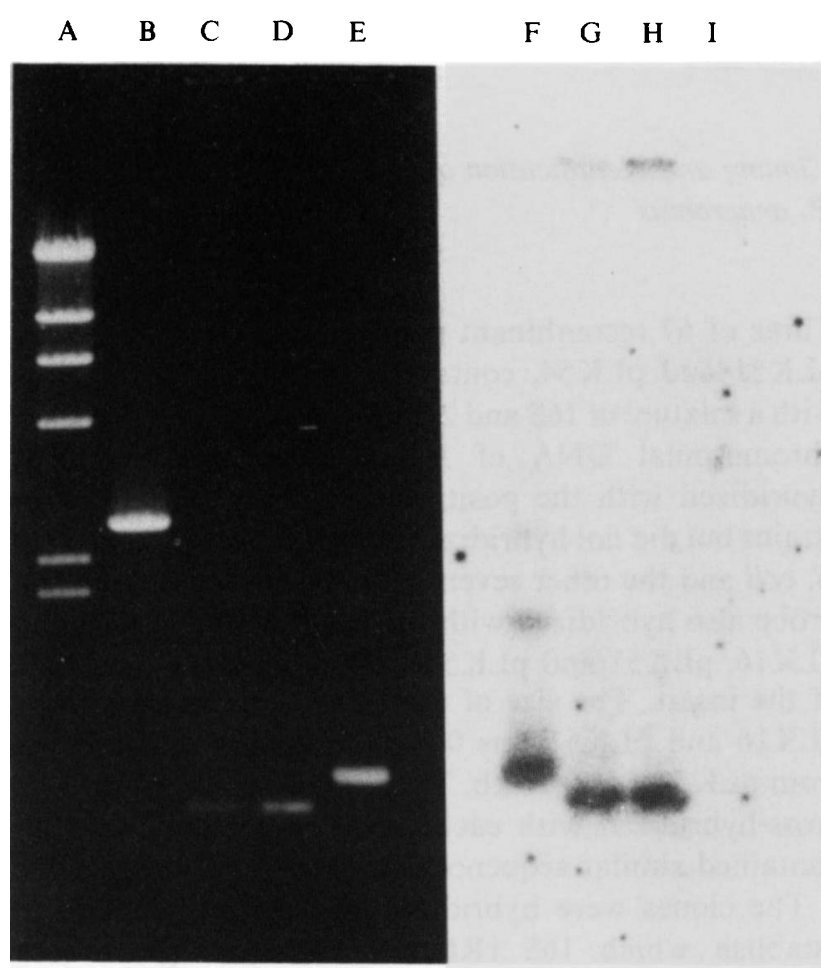

Fig. 1. Identification of $16 \mathrm{~S}$ rRNA sequences in recombinant plasmids. The HindIII inserts in pLK16, pLK51 and pLK54 in $1 \%$ agarose gel (lanes A-E) were transferred to nylon membrane and hybridized with ${ }^{32} \mathrm{P}$ end-labelled primer 3 which contained consensus E. coli $16 \mathrm{~S}$ rRNA sequences (lanes F-I). Lanes: A, $\lambda$ HindIII markers $(23 \cdot 1,9 \cdot 4,6 \cdot 6,4 \cdot 4,2 \cdot 3,2 \cdot 0$ and $0.56 \mathrm{~kb}) ; \mathrm{B}$ and $\mathrm{I}, \mathrm{pUC} 9$ digested with HindIII; C and H, 0.84 kb HindIII fragment of pLK16; D and G, $0.84 \mathrm{~kb}$ HindIII fragments of pLK $51 ; \mathrm{E}$ and F, $0.98 \mathrm{~kb} H$ HindIII fragment of pLK54.

\section{Chromosomal DNA fingerprinting by RFLP}

The fragment sizes of DNA fragments generated by HindIII digestion of the eight ATCC strains as well as the 20 clinical isolates differed. HindIII digestion of $P$. indolicus ATCC 29427, $P$. tetradius ATCC 35098 and $P$. productus ATCC 27340 produced fragments greater than $30 \mathrm{~kb}$ in size while digestion of the other species with HindIII generated fragments smaller than $23 \mathrm{~kb}$. HindIII digestion of $P$. prevotii ATCC 9321 produced the smallest fragments (less than $10 \mathrm{~kb}$ ) among the Peptostreptococcus isolates studied (data not shown). The EcoRI fragments resolved in $0.8 \%$ agarose gels for all the ATCC strains were larger than those obtained with HindIII digestion. Although the DNA fragments ranging in size between 3 and $30 \mathrm{~kb}$ resolved well in $0.8 \%$ agarose in TA buffer, the resolution of smaller fragments (less than $3 \mathrm{~kb}$ ) was poor due to diffusion of the DNA. Therefore, differences between strains were only noted for the larger fragments and complete restriction endonuclease profiles of the

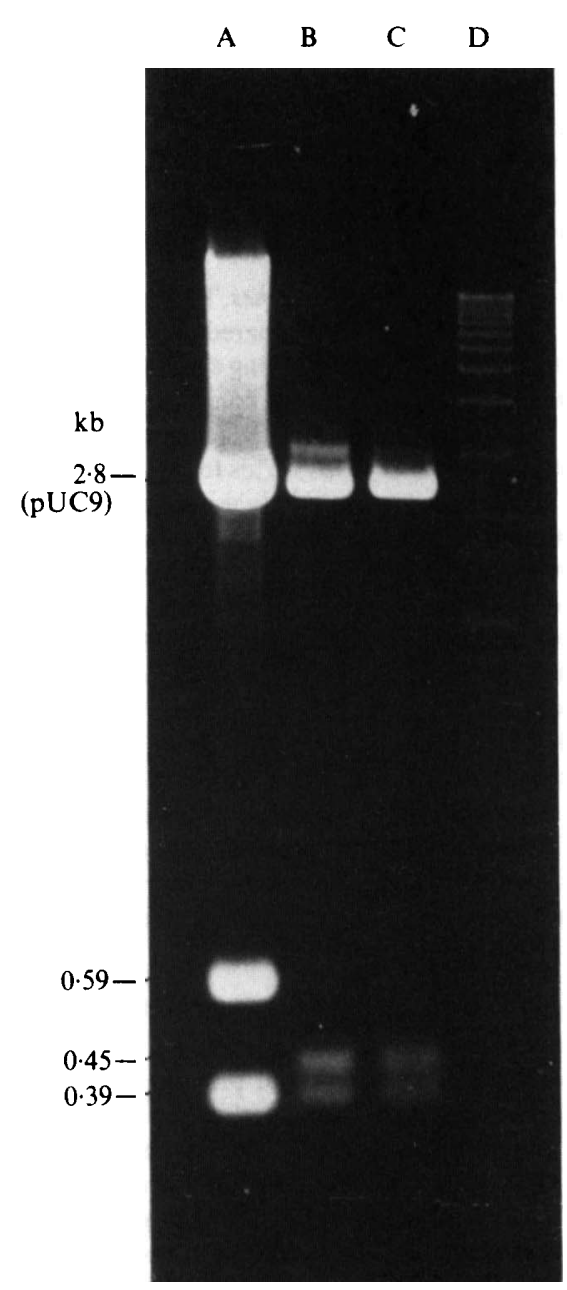

Fig. 2. Agarose gel electrophoresis of HindIII/SmaI-restricted plasmid DNA. Lanes: A, pLK 54; B, pLK 51; C, pLK 16; D, 1 kb molecular size markers. The sizes of the HindIII/SmaI fragments are indicated on the left.

numerous HindIII or EcoRI were not recorded. This presented more difficulty in comparison of EcoRI restriction endonuclease profiles because they contained more large fragments than HindIII digests. The resolution of the HindIII and EcoRI fragments also depended on the amount of DNA loaded. Therefore, restriction endonuclease profiles will be of limited use for the differentiation of Peptostreptococcus isolates.

The determination of the RFLP pattern of $r r n$ operons was evaluated as a tool for inter- and intra-species differentiation of Peptostreptococcus isolates. The nonradiometric labelling method showed better resolution than ${ }^{32} \mathrm{P}$-labelled probes for fragments of similar size because the hybridization bands were sharper. For example, the 2.8 and $2.95 \mathrm{~kb}$ HindIII fragments of PAl and PA3 (Fig. 3, lanes A and C) were observed as double bands when hybridized with non-radioactive probe $\mathrm{B}$ but 


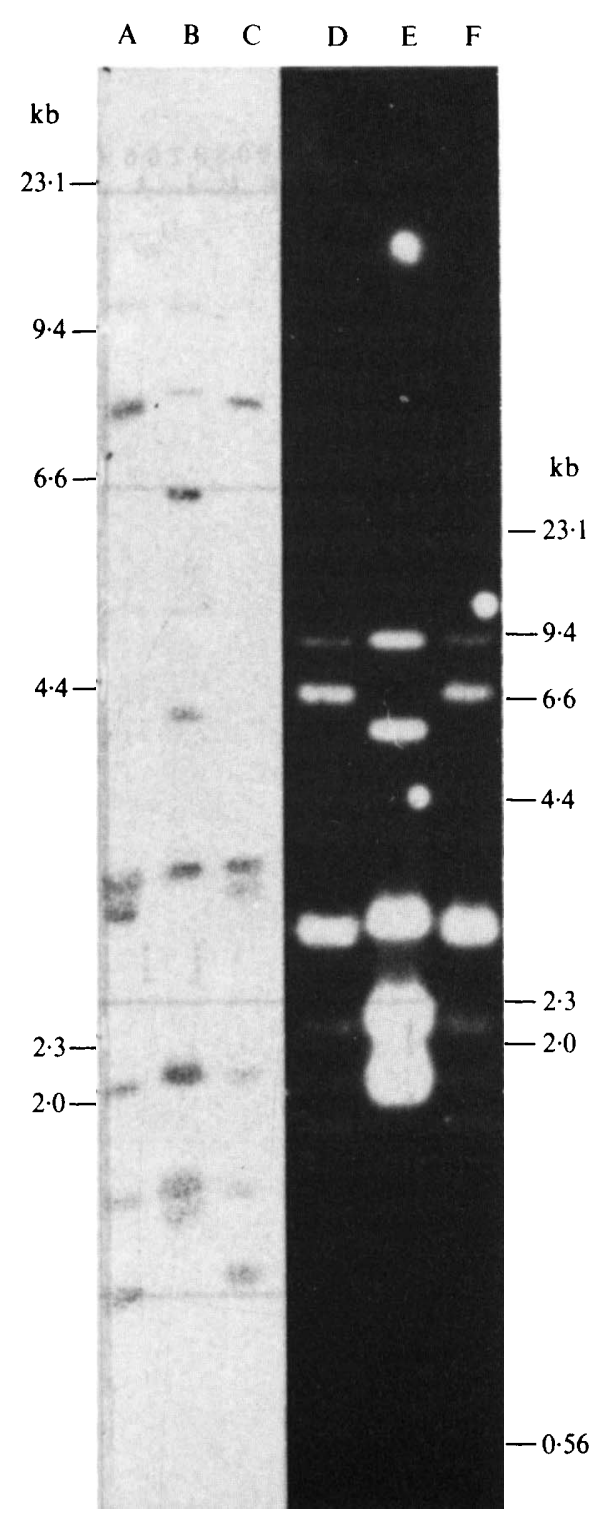

Fig. 3. Comparison of RFLPs generated by non-radioactive and radioactive probes. Two Southern blots of $P$. asaccharolyticus DNA digested with HindIII were hybridized with non-radioactive probe $\mathrm{B}$ (lanes $A-C$ ) and radioactive probe $C$ (lanes D-F). Lanes: $A$ and $D$, PA1; B and E, PA2; C and F, PA3. The sizes of $\lambda$ HindIII markers are shown on the left and right. The bands in lane $A$ were distorted during electrophoresis.

as a single band for the radioactive probe $\mathrm{C}$ (Fig. 3, lanes $\mathrm{D}$ and $\mathrm{F}$ ).

The RFLPs of the 20 isolates from five Peptostreptococcus spp. produced by hybridization of either EcoRI- or HindIII-digested chromosomal DNA with probes A (HindIII insert of pLK54), B (BamHI-PstI fragment of pKK 3535) or C (mixture of $16 \mathrm{~S}$ and 23S rRNA) are summarized in the schematic representation in Figs 4 and 5, respectively. The sizes of the fragments reported in this study were means of two to four determinations.
The differences between runs for small fragments (under $5 \mathrm{~kb}$ ) did not vary more than $0.5 \mathrm{~kb}$; however, larger fragments $(>10 \mathrm{~kb})$ varied as much as $2-3 \mathrm{~kb}$, corresponding to a millimetre difference in the measurement of mobility between gels. To overcome this problem, reference ATCC strains were included in each gel to allow accurate alignment of fragments of the same size. For the schematic representation (Figs 4 and 5) of the common bands, the sizes are the means of the bands from all the strains.

Interspecies differentiation of the five Peptostreptococcus spp. based on RFLP was observed by comparing the profiles obtained by using probe A, B or C. Four $P$. anaerobius strains had a common $6.1 \mathrm{~kb}$ EcoRI band (Fig. 4) and a common $3.5 \mathrm{~kb}$ HindIII band (Fig. 5) when probe A hybridized to the fractionated DNA. Speciesspecific bands were also observed for $P$. asaccharolyticus, $P$. magnus and $P$. micros, but not for $P$. prevotii (Figs 4 and 5). Although $P$. prevotii showed no intraspecies homogeneity, the RFLPs of $P$. prevotii strains were distinct from those of the other four species studied.

Intraspecies differentiation of strains was observed for all the Peptostreptococcus spp. studied. The four $P$. anaerobius strains had unique as well as common bands in their RFLP patterns generated by the hybridization of $E c o$ RI fragments with probe A. For example, $P$. anaerobius $\mathrm{Pl}$ had a $7.65 \mathrm{~kb}$ Eco RI band instead of the $7 \cdot 2 \mathrm{~kb}$ EcoRI band of P. anaerobius ATCC 27337 (Fig. 4). The size of some of the unique bands varied only slightly between strains (compare the $4.95 \mathrm{~kb}$ EcoRI band from the ATCC 27337 profile and the $5 \cdot 1$ and $5.0 \mathrm{~kb}$ bands of P2 and P3, respectively: Fig. 4). In order to observe this slight difference, the digested DNA from these strains was fractionated side by side in each gel. P. asaccharolyticus isolates PA1, PA3, PA5 and PA6 showed very closely related RFLP profiles (Figs 4 and 5). By contrast, the RFLPs of $P$. asaccharolyticus from our culture collection differed significantly from ATCC 14963 (Figs 4 and 5), making it difficult to establish a genetic relationship between the clinical isolates and the ATCC strain. Analysis of RFLP profiles from P. magnus also showed that strains from our collection were more closely related to each other than to P. magnus ATCC 15794. However, unlike the $P$. asaccharolyticus profiles, common bands were observed in both EcoRI- and HindIII-generated $P$. magnus RFLP profiles of clinical isolates and ATCC strain (Figs 4 and 5). As mentioned previously, P. prevotii strains contained only unique bands in their RPLF profiles (Figs 4 and 5).

\section{Comparison of probes}

The three rRNA probes used in this study differed in size, ranging from about $1 \mathrm{~kb}$ (probe $\mathrm{A}$, partial $16 \mathrm{~S}$ 


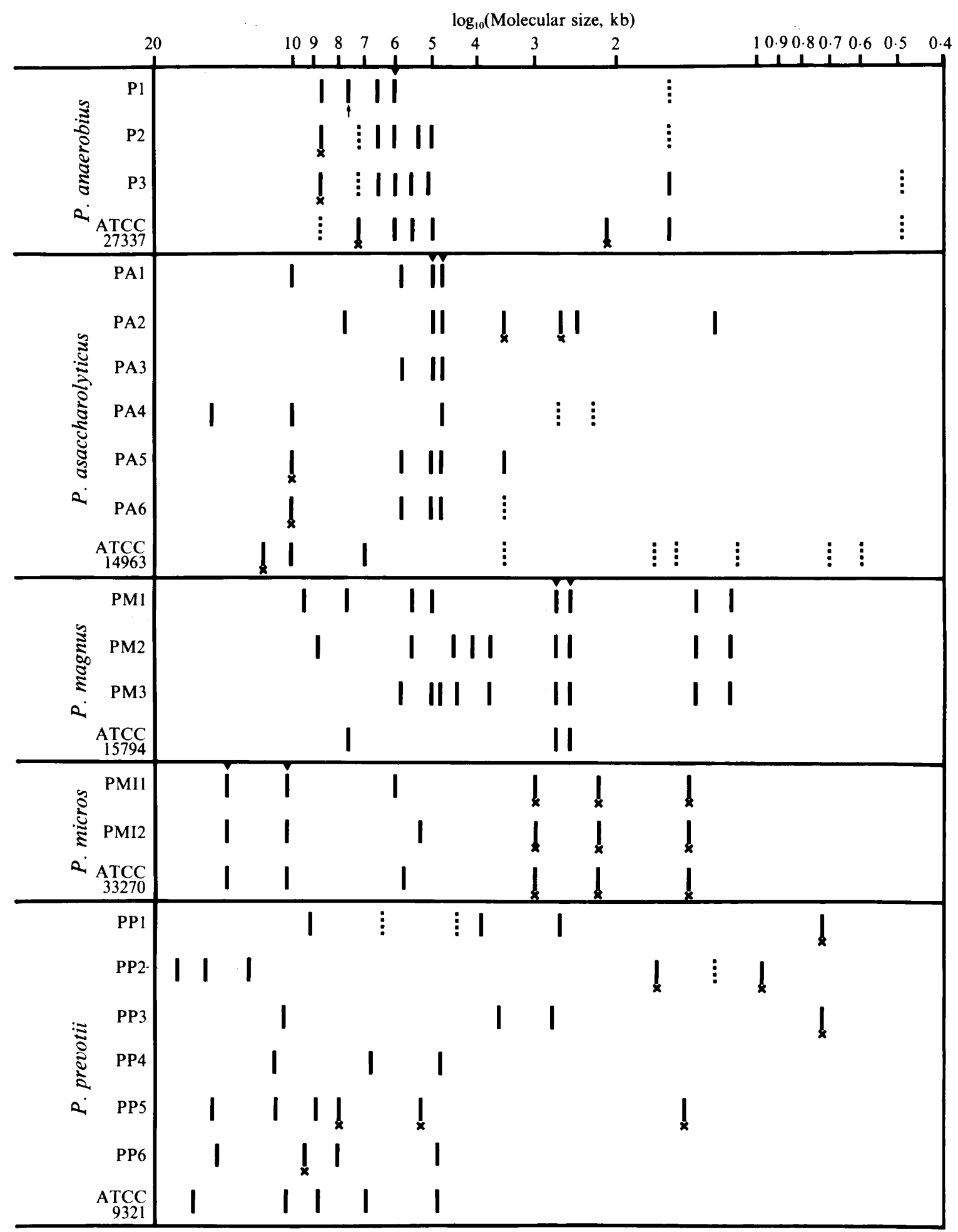

Fig. 4. Schematic representation of RFLPs of rRNA genes generated by hybridization of EcoRI fragments of chromosomal DNA from

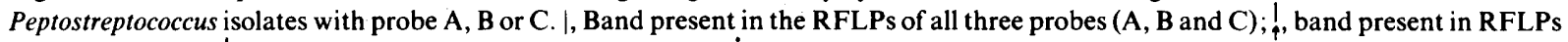
of probes $A$ and $B ;,$, band present in RFLPs of probes $B$ and $C ; \vdots ;$, band found in the RFLP of probe $B$ only. $\nabla$, on top margins, indicates common bands present between strains within the same species. The sizes of the fragments in Figs 4 and 5 were means of at least two determinations as described in Results. 


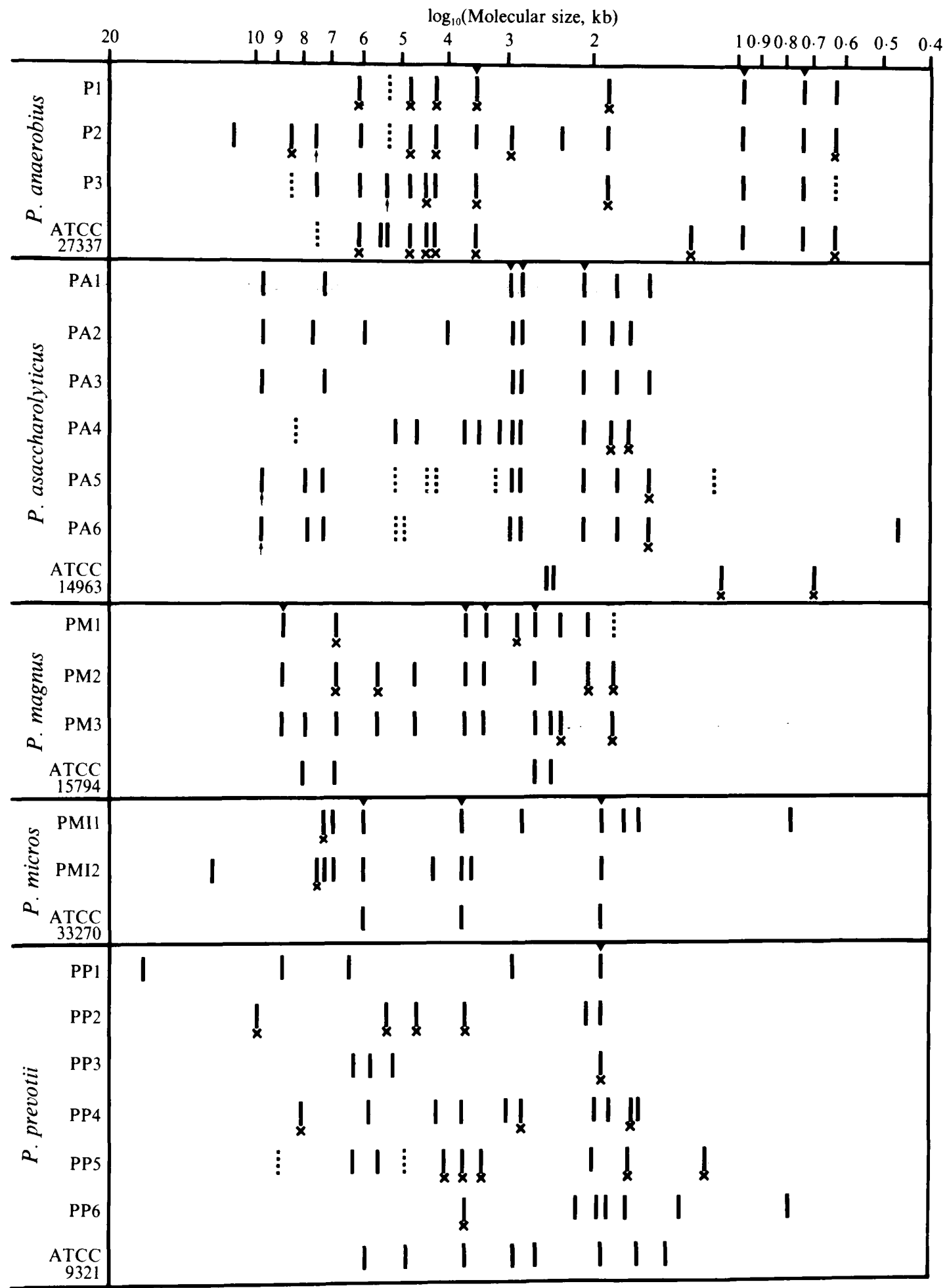

Fig. 5. Schematic representation of RFLPs of rRNA genes generated by hybridization of HindIII fragments of genomic DNA from Pentostreptococcus isolates with probe A, B or C. Symbols are as for Fig. 4. 
rRNA gene from $P$. anaerobius) to $7.2 \mathrm{~kb}$ (probe $\mathrm{B}$, the entire rRNA operon from $E$. coli). Therefore, the number of bands for each RFLP profile generated by using different-sized probes would vary depending on the location and number of HindIII or EcoRI sites within the rRNA genes. From our data (Figs 4 and 5), the number of bands generally increased with more rRNA sequences in the probe, indicating that the additional bands were due to the additional $23 \mathrm{~S} r R \mathrm{NA}$ in probe $\mathrm{C}$ or $23 \mathrm{~S}$ and $5 \mathrm{~S}$ rRNA sequences in probe $B$. In a few cases $(8.5 \mathrm{~kb}$ HindIII fragment of $P$. anaerobius; $5.55 \mathrm{~kb}$ EcoRI fragment of $P$. anaerobius $\mathrm{Pl}$; and the $8.5 \mathrm{~kb}, 7.0 \mathrm{~kb}$, $5.9 \mathrm{~kb}$ and $5.0 \mathrm{~kb}$ EcoRI fragments of $P$. asaccharolyticus PA4) additional bands for probe $\mathrm{C}$ as compared to probe $\mathrm{B}$ were observed but not included in Figs 4 and 5. The presence of these additional bands could be due either to the specificity of the probes which allowed hybridization of sequences with a higher percentage of mismatch or to differences in the sequences of rRNA from different operons of the E. coli chromosome. However, there are cases where no difference was observed between probes. For example, the same RFLPs were observed when the $E c o$ RI fragments of $P$. magnus strains were hybridized with one of the three probes (Fig. 4).

\section{Discussion}

The determination of RFLPs based on rRNA genes has been previously applied to differentiate species and strains of mycoplasmas and revealed genotypic heterogeneity among Acholeplasma laidlawii and Mycoplasma hominis strains but homogeneity among $M$. pneumoniae strains (Yogev et al., 1988). This study demonstrates that it is possible to use this method to differentiate Peptostreptococcus isolates also. By this technique, $P$. anaerobius, $P$. magnus and $P$. micros isolates could be grouped as separate species. This corresponded to results based on identification using conventional methods. Thus, chromosomal DNA fingerprinting by RFLP is potentially useful either for confirming the identity of phenotypically atypical strains of these three Peptostreptococcus spp. or for differentiating phenotypically similar $P$. magnus and P. micros isolates (Moore et al., 1987). The RFLPs of $P$. asaccharolyticus showed that the clinical isolates of this species were more similar to each other than to the type strain P. asaccharolyticus ATCC 14963. This result agrees with DNA homology studies which showed that the clinical isolates were more homogeneous among themselves than to $P$. asaccharolyticus ATCC 14963 (Moore et al., 1986). Thus, we conclude that, for the molecular typing of Peptostreptococcus isolates, the choice of ATCC 14963 as a reference strain is undesirable. The heterogeneity of the RFLPs based on EcoRI and HindIII digests of chromosomal DNA from $P$. prevotii isolates suggested that this species probably comprised strains that were genetically more diverse than the other four species studied. This is supported by the relative heterogeneity of pre-formed enzyme patterns of $P$. prevotii (Murdoch et al., 1988).

The chromosomal DNA of Peptostreptococcus species contained many HindIII and EcoRI sites. Because the fragments generated were small they could be resolved without pulsed-field electrophoresis apparatus. However, the numerous fragments produced by these digestions presented problems in recording and comparison. Thus, the use of restriction endonuclease profiles alone cannot be recommended for use in molecular typing of Peptostreptococcus isolates. Hybridization of $E c o$ RI and HindIII fragments with probes for $r r n$ operons reduced the number of fragments, thereby making comparisons easier. The determination of RFLP patterns is therefore, a better method than restriction endonuclease analysis for molecular typing of peptostreptococci.

Although all the three probes produced useful RFLPs for the differentiation of peptostreptococci, both probes A (HindIII fragment from pLK54) and $\mathrm{B}(7.2 \mathrm{~kb}$ Bam HI-Pst fragment of pKK 3535), in contrast to probe C (16S and 23S rRNA from E. coli), provided better resolution of fragments of related sizes using the nonradiometric labelling method as compared to the radiometric method. Probe $A$ is probably a better choice than probe $B$ for further use in peptostreptococcal typing because it contained cloned 16S rRNA gene sequences from $P$. anaerobius which were more similar to the $16 \mathrm{~S}$ rRNA gene sequences from other peptostreptococci than to those from $E$. coli. This was reflected by the ability of probe A to hybridize with DNA fragments containing 16S rRNA gene sequences at higher stringency conditions $\left(63^{\circ} \mathrm{C}\right)$. Furthermore, probe $\mathrm{A}$ did not require an extra $E c o$ RI digest of fragments prior to labelling, a step required for probe $\mathrm{B}$. As a result, it was less dependent on hybridization conditions or on the actual size of labelled probes to obtain reproducible results.

This study shows that the determination of RFLPs of $r r n$ operons is a potentially useful method for the identification and differentiation of Peptostreptococcus species, especially when used in conjunction with other taxonomic methods. It would be interesting to compare this method with other identification schemes such as pre-formed enzyme detection in the distinction of $P$. magnus and P. micros (Murdoch et al., 1988). However, one limitation of the RFLP method for taxonomic or identification purposes is the lack of standardized methods for recording RFLPs (Grimont \& Grimont, 1986) for the establishment of databanks. This also presents a problem in comparing data from different gels 
or between laboratories. Therefore, RFLP determination may be limited to differentiating small numbers of bacterial strains such as those involved in outbreaks or from patients with treatment failure or relapses. For the determination of RFLP of rrn operons of Peptostreptococcus species, the cloned partial 16S rRNA HindIII fragment was more efficient than probes containing $E$. coli rRNA sequences.

We thank Dr J. Brosius for supplying pKK 3535 and D. Auger and C. Galvis for their technical assistance.

\section{References}

BIRnBoIm, H. C. \& Doly J. (1979). A rapid alkaline extraction procedure for screening recombinant plasmid DNA. Nucleic Acids Research 7, 1513-1523.

Bougault, A. M., Rosenblatt, J. E. \& Fitzgerald, R. H. (1980). Peptococcus magnus: a significant human pathogen. Annals of Internal Medicine 93, 244-248.

BROOK, I. (1987). Bacterial synergy in pelvic inflammatory disease. Archives of Gynecology and Obstetrics 241, 133-143.

Brook, I. \& WALKER, R. I. (1984). Pathogenicity of anaerobic grampositive cocci. Infection and Immunity 45, 320-324.

Brosius, J., Ullrich, A., Raker, M. A., Gray, A., Dull, T. J., Gutell, R. R. \& Noller, H. F. (1981). Construction and fine mapping of recombinant plasmids containing the $r r n \mathrm{~B}$ ribosomal RNA operon of $E$. coli. Plasmid 6, 112-118.

Ezaki, T., Yamamoto, N., Ninomiyer, K., Suzuki, S. \& YabuUchi, E. (1983). Transfer of Peptococcus indolicus, Peptococcus asaccharolyticus, Peptococcus prevotii, and Peptococcus magnus to the genus Peptostreptococcus and proposal of Peptostreptococcus tetradius sp. nov. International Journal of Systematic Bacteriology 33, 683-698.

FINEGOLD, S. M. (1989). General aspects of anaerobic infection. In Anaerobic Infections in Humans, pp. 137-153. Edited by S. M. Finegold \& W. L. George. San Diego: Academic Press.

GARBER, G. E. \& CHOW, A. W. (1989). Female genital tract infections. In Anaerobic Infections in Humans, pp. 429-453. Edited by S. M. Finegold \& W. L. George. San Diego: Academic Press.
Grimont, F. \& Grimont, P. A. D. (1986). Ribosomal ribonucleic acid gene restriction patterns as potential taxonomic tools. Annales de l'Institut Pasteur/Microbiologie 137B, 165-175.

Holdeman, L. V., Cato, E. P. \& Moore, W. E. C. (1977). Anaerobe Laboratory Manual, 4th edn. Blacksburg: Virginia Polytechnic Institute and State University.

Lane, D. J., Pace, B., Olsen, G. J., Stahl, D. A., Sogin, M. L. \& PACE, N. R. (1985). Rapid determination of 16 S ribosomal RNA sequences for phylogenetic analyses. Proceedings of the National Academy of Sciences of the United States of America 82, 6955-6959.

MARDH, P.-A. \& WESTROM, L. (1984). Factors that might influence the outcome of studies on the aetiology and epidemiology of acute pelvic inflammatory disease. Scandinavian Journal of Gastroenterology 19, 73-86.

Moore, L. V. H., Johnson, J. L. \& Moore, W. E. C. (1986). Genus Peptostreptococcus Kluyver and van Niel 1936, 401. In Bergey's Manual of Systematic Bacteriology, vol. 2, pp. 1083-1092. Edited by P. H. A. Sneath, N. S. Mair, M. E. Sharpe \& J. G. Holt. Baltimore: Williams \& Wilkins.

Murdoch, D. A., Mitchelmore, I. J. \& Tabaqchali, S. (1988). Identification of Gram-positive anaerobic cocci by use of systems for detecting pre-formed enzymes. Journal of Medical Microbiology 25, 289-293.

NG, L.-K. \& Dlllon, J. R. (1989). Plasmid analysis and antimicrobial susceptibilities of Peptostreptococcus species. FEMS Microbiology Letters 61, 47-52.

Pérolat, P., Grimont, F., Regnault, B., Grimont, P. A. D., Fournié, E., Thevenet, H. \& Baranton, G. (1990). rRNA gene restriction patterns of Leptospira: a molecular typing system. Research in Microbiology 141, 159-171.

SambrooK, J., Fritsch, E. F. \& Maniatis, T. (1989). Molecular Cloning: a Laboratory Manual, 2nd edn. Cold Spring Harbor, NY: Cold Spring Harbor Laboratory.

Smith, G. L. F., Cumming, C. G. \& Ross, P. W. (1986). Immunochemical characterization of the cell surface carbohydrate antigens of Peptostreptococcus anaerobius. Journal of General Microbiology 132, 525-530.

SOUTHERN, E. (1975). Detection of specific sequences among DNA fragments separated by gel electrophoresis. Journal of Molecular Biology 98, 503-517.

SWEET, R. L. (1986). Pelvic inflammatory disease. Sexually Transmitted Diseases 13, S192-198.

Yogev, D., Halachmi, D., KenNy, G. E. \& Razin, S. (1988). Distinction of species and strains of mycoplasmas (Mollicutes) by genomic DNA fingerprints with an rRNA gene probe. Journal of Clinical Microbiology 26, 1198-1201. 